\title{
Communities of faith and the global family planning movement: friends or foes?
}

\author{
Rebecca Oas ${ }^{\mathrm{a}}$
}

a PhD, Associate Director of Research, Center for Family and Human Rights (C-Fam), New York, NY, USA

Within the Christian community, diverse views exist on the theological and moral dimensions of family planning, and specifically of contraception. Discussion of these issues frequently focuses on family planning as a collection of methods and commodities used to space or limit pregnancies. Often missing from the discussion is the notion of family planning as a social and political movement, and the degree to which this movement's philosophy and goals are compatible with Christian theology. Nevertheless, faith-based aid organizations, including those with no objection to contraceptive use, must seriously grapple with the moral and practical implications of partnering with institutions that promote an approach to family planning that is at odds with Christian values.

For purposes of this discussion, the international family planning movement is taken to consist of the network of organizations whose primary purpose is advocacy for and provision of family planning. In contrast to many international aid groups, Christian and otherwise, which seek a variety of solutions to the specific problems of a given country or region, the dominant discourse within this family planning movement has tended to advance one type of solution-contraception, often with abortion as a backup, although the rationale for doing so often changes. Over the last century, the dominant discourse of the family planning movement has shifted multiple times, from a focus on eugenics and population control to a focus on women's rights and empowerment, and then to a public health rationale aiming to reduce maternal and child deaths. ${ }^{1}$ More recently, the case for fertility reduction for its own sake has begun to reappear in connection with the global concern about climate change and environmental sustainability. ${ }^{2}$ While family planning advocacy invokes a wide range of problems, the proposed solution remains the same.

\section{You shall not kill (Exodus 20:13)}

For leading family planning organizations including the International Planned Parenthood Federation and Marie Stopes International, advocacy for abortion as well as contraception is a defining aspect of their work. Nevertheless, according to international consensus among UN member countries, as well as U.S. law, family planning is explicitly defined as excluding abortion., ${ }^{3,4}$ This agreed definition made it possible for the delegation of the Holy See to accept the conclusions of the International Conference on Population and Development at Cairo in 1994, albeit with reservations clearly stating their unchanged position on artificial contraceptive methods and the immorality of abortion independent of its legality. ${ }^{3}$ This conference, convened by the UN, and its resulting Program of Action which guides the work of the United Nations Population Fund, not only separated the definition of family planning from abortion, but stated that the legality of abortion was a matter for individual governments to determine and not an international human right.

July 2017. Christian Journal for Global Health, 4(2):3-9. 
To the extent that family planning is understood to exclude abortion, some Christian aid organizations have been able to justify providing family planning methods, inasmuch as the methods they offer are otherwise deemed morally acceptable. But for Christian groups that oppose abortion, the dominant discourse within the family planning movement may not be tolerant of silent recusal. Philanthropist Melinda Gates drew criticism from many within the movement for "stigmatizing" abortion by not directly supporting it. ${ }^{5}$ At the same time, Gates provides support to organizations that also advocate for abortion and was critical of U.S. President Donald Trump for his reinstated and expanded Mexico City Policy which blocks federal funds to abortion-promoting organizations. ${ }^{6}$ For those within the Christian community who view abortion as the intentional destruction of innocent human life, Gates' policy of silence on the abortion issue received some praise, but fell short of achieving her aim of "no controversy." When combined with funding of family planning organizations who actively promote abortion, her silence arguably signaled not condemnation, but consent. Again, a clear distinction must be drawn between family planning as methods to prevent pregnancy and the family planning movement as a global advocacy juggernaut with strong ties to abortion. Determining what level of engagement Christian agencies should have with organizations, governments, and multilaterals whose values conflict with Christian values is a complex ethical question that requires in-depth biblical and ethical consideration. In December, 2014, USAID's Advancing Partners and Communities Project (APC) supported a meeting by Christian Connections for International Health $(\mathrm{CCIH})$ titled Faith Matters: International Family Planning from a Christian Perspective. Its concluding report presented CCIH's definition of family planning as excluding abortion. It was perhaps commendable that $\mathrm{CCIH}$ was able to articulate such a position and have it included, given the fact that the implementing partners of APC, John

July 2017. Christian Journal for Global Health, 4(2):3-9.
Snow International (JSI) and FHI 360, had explicitly promoted abortion, if not as family planning per se, as part of their broader advocacy.,8

The existing balance that enables Christian groups to accept government funding - and ensures their eligibility for such grants - is supported by a combination of U.S. laws and policies and international standards that separate family planning from abortion. But these safeguards are under constant assault from many family planning organizations that oppose that separation. JSI, for example, has signed statements calling for both the repeal of the Mexico City Policy and the redefinition of the Helms Amendment to create exceptions in the ban on U.S. funding for overseas abortions. Sneha Barot of the Guttmacher Institute, which advocates for both abortion and family planning, is strongly critical of the Helms Amendment: "Just on its face, the law is extreme and harmful." "Elsewhere, Barot acknowledges the "essential safety net" provided by faith-based organizations overseas, and the fact that in some areas, they may be the only providers of essential services. She notes that faith-based groups' eligibility for U.S. family planning funding balances morally-based objections to particular methods against a requirement that they offer referrals to a wider range of services than they might be willing to offer directly ${ }^{10}$ If the Guttmacher Institute and its allies successfully advocate Congress to repeal the Helms Amendment, Christian aid organizations might find themselves pressured to refer for abortions as well, or be ineligible for U.S. funding, which could in turn jeopardize much-needed aid in fragile and poor settings.

\section{What is truth? (John 18:38)}

In recent decades, the dominant mostly western-based organizations within the family planning movement have been highly successful in convincing national and international institutions to adopt a range of definitions and measurements designed primarily as tools for family planning 
advocacy. The concept of "unmet need" has been characterized as an "invaluable bridge" between demographic and rights-based rationales for promoting family planning. "Unmet need" has been criticized by economists as better suited to advocacy than an actual measure of demand for products or services. ${ }^{12}$ Furthermore, "unmet need" is frequently mischaracterized by organizations within the family planning movement as lack of access, despite the fact that far more women described as having a "need" cite personal opposition or concerns about health risks than cost or accessibility issues. ${ }^{13}$

As a result of the widespread misuse of "unmet need" by policymakers and advocacy groups alike, there is an illusion of high demand for family planning within developing regions. This in turn leads to costing projections like the 2014 Adding It Up report co-published by the United Nations Population Fund and the Guttmacher Institute, which estimates that an annual $\$ 9.4$ billion could meet the total "need" for family planning, based on the assumption "that all women with unmet need would use modern contraceptives." 14 This assumption gains little support from the Guttmacher Institute's own analysis, which reveals that most contraceptive nonuse is a matter of personal choice rather than lack of access. ${ }^{13}$ Yet modeling programs like the Lives Saved Tool are used to estimate the impact of increased family planning use, for only the cost of providing commodities, in terms of averted deaths of women and children. In some cases, estimates of averted child deaths include children whose hypothetical deaths in infancy might be averted by preventing their conception. In the report Acting on the Call published by USAID, these were referred to as "child lives saved from demographic impact," proposing an innovative way in which a life could be saved without leaving a survivor. ${ }^{15}$

It is likewise essential to consider the impact of definitions. While family planning may be considered to exclude abortion, it rarely excludes contraceptive methods that may have abortifacient effects, such as some types of intrauterine devices. Such methods are classified as "contraceptive" if they prevent "pregnancy," as defined as being established at implantation rather than conception. ${ }^{16}$ Essentially, this definition not only redefines pregnancy but also entirely fails to consider when human life begins, which is arguably the more important question.

Similarly, while "contraception" and "family planning" are often used interchangeably, fertility awareness-based methods of family planning, the only methods permitted by Catholic teaching, are morally permissible precisely because they are not contraceptive. In other words, they are not intended to render the act of sexual intercourse nonprocreative, or, in the words of the encyclical Humanae Vitae by Pope Paul VI, are not intended to separate "the unitive significance and the procreative significance which are both inherent to the marriage act." ${ }^{\prime 17}$ While it makes sense on a semantic level to exclude these methods from classification as "modern contraceptive methods," as has been proposed by some within the family planning community, the intent of this proposal is to classify such methods not as "non-contraceptive," but rather as "non-modern."18 This would have the effect of reducing funding and support for fertility awarenessbased methods of family planning within national and international policy, particularly as the current indicator for family planning within the Sustainable Development Goals specifies that "need" for family planning be satisfied by modern methods.

Christian and other aid organizations would do well to critically examine the measurements and methodologies used by family planning groups, primarily as a means of advocacy, and frequently without internal consistency. For Christian entities, the imperative to speak with honesty must be paramount, and a source of common ground between denominations divided over the contraceptive issue. If the goal is to ensure that women and children have better health outcomes in resource-limited settings, it is counterproductive to use measurements of progress designed to privilege family planning over other interventions. Furthermore, if the goal is to

July 2017. Christian Journal for Global Health, 4(2):3-9. 
ensure that women have access to family planning, better measures of access are needed, preferably originating from entities that do not have a direct stake promoting particular forms of contraception and abortion. Christian organizations might lead the way in this regard, but they may need to part company with many organizations in the family planning establishment, and even actively compete with them to set international norms and standards.

\section{Be fruitful and multiply (Genesis 35:11)}

Central to the "sexual revolution" is the principle that the sexual act must be uncoupled from the potential for procreation. This goal, promoted by the development of modern contraceptives, has proven extremely difficult to accomplish, even with them. Despite the fact that approximately $40 \%$ of pregnancies worldwide are designated as "unintended," the international family planning movement continues to rely on definitions of pregnancy as "unintended," "unwanted," "mistimed," and "unplanned," all of which "assume that pregnancy is a conscious decision." ${ }^{19,20}$ Advances in global development and medicine have driven down maternal and child mortality, but gaps remain, linked to poverty and resource inequity. Although Africa is the global region with the highest rates of maternal and child mortality as compared with the number of live births (defined by the UN as the maternal mortality ratio and the under-5 mortality rate), it is also the region with the lowest percentage of pregnancies classified as unintended $(35 \%))^{21,22,19}$ It is important to note that the terminology of "intendedness" (and, similarly, of "wantedness") originates from fertility surveys designed and intended to promote contraception and abortion, and which have no interest in promoting the acceptance of children whose conceptions were not "planned." Perhaps the best illustration of this point is the frequency with which attempts to measure "unintended" births refer to the problem of "retroactive rationalization"- that is, parents who not only come to accept their unexpected child, but deny having ever wished to avoid or postpone the pregnancy. ${ }^{23}$ This is typically regarded as an unfortunate flaw in the data that masks the true scale of the problem of unintended pregnancies, rather than evidence that the problem is, to an extent, selfsolving. Furthermore, decades of studies seeking to demonstrate that "unintended" or "unwanted" children fare worse than their counter-parts have produced inconsistent and under-whelming findings, once confounding variables are accounted for. The third edition of the World Bank's Disease Control Priorities stated in summary that "[i]nsufficient data exist to indicate whether unintended pregnancies carried to term are disadvantaged in health or schooling, compared with intended births." 24

Within the international family planning movement, there is little acknowledgment that unplanned pregnancies or abortions might be addressed by any intervention apart from contraceptives. In a 2015 article in Demography authors Kathryn Kost and Laura Lindberg, both of the Guttmacher Institute, clearly articulate this position: "[T]he public health goal is not to help mothers change their attitudes so that those unintended births become intended ones; the goal is to delay those pregnancies until women move into a life stage when they do want to have a baby ... Similarly, the negative consequences for an unwanted birth can be alleviated not by convincing mothers to want the births, but by preventing the unwanted pregnancies." 25 Christian aid organizations, who are often a front line of assistance for women with crisis pregnancies both at home and abroad, have a duty to ensure that their message is one of hope and resilience for both mother and child. This mission is not only outside the agenda of many organizations in the international family planning movement, but it also starkly refutes many of their core principles.

July 2017. Christian Journal for Global Health, 4(2):3-9. 


\section{Bad company corrupts good morals (1}

\section{Corinthians 15:33)}

Many leading family planning organizations have made great strides in reaching out to the Christian community to form partnerships, particularly around the goal of ending preventable deaths and reducing poverty. To the extent that religious leaders within local communities are seen as powerful gatekeepers, this may be a sensible strategic move. But whether Christian organizations providing aid at the local, national, or international level stand to benefit from such partnerships - or can justify them at a moral and ethical level — remains to be seen. For all its attempts at outreach to faith groups, most organizations within the family planning movement have remained stubbornly committed to promoting abortion, whether they regard it officially as a method of family planning or not. ${ }^{26}$ They continue to push for institutional acceptance of definitions and measurements better suited to promoting the interests of their own organizations than the general public good. In recent years, the dominant discourse within the family planning movement has moved to favor "sexual and reproductive health and rights," a construct that remains highly controversial within international institutions, and is typically defined as encompassing a set of norms that are on a direct collision course with a traditional Christian concept of the dignity of the human person, sexual morality, and the nature of the family. ${ }^{27}$

Christian organizations engaged in international family planning work face a choice with important moral implications: navigate their own course in parallel to or sometimes in competition with organizations in the family planning movement, or engage to speak prophetically and help guide the movement away from abortion as a solution and amoral principles which are antithetical to Christian morality. However, this approach risks inviting organizations into their much-needed and faith-inspired efforts, which could dilute or challenge their moral beliefs. Whatever choices Christian groups ultimately make in this regard, they should be fully aware of the baggage the global family planning movement carries with itand shows no indication of letting go.

\section{References}

1. A good summary of these shifting rationales can be found in the discussion between former heads of the USAID's Office of Population and Reproductive Health, held at the Wilson Center, Washington D.C., on June 26, 2015. Summary and webcast can be found at https://www.wilsoncenter.org/event/changing-theworld-how-usaids-50-years-family-planning-hastransformed-people-economies-and

2. Aspen Global Health and Development. The population-climate connection: why family planning is a win-win for women and the planet. Global Leaders Council for Reproductive Health. Aspen Global Health and Development at the Aspen Institute. Aspen Institute, Dec 2011.

3. Report of the International Conference on Population and Development (ICPD), 18 October 1994.

A/CONF.171/13. Available from: www.un.org/popin/icpd/conference/offeng/poa.html

4. USAID, Global Health Legislative \& Policy Requirements, updated May 2017. Available from: https://www.usaid.gov/what-we-do/globalhealth/cross-cutting-areas/legislative-policyrequirements

5. Kohn S. A plea to Melinda Gates: stop stigmatizing abortion. The Daily Beast. 5 June 2014. Available from: http://www.thedailybeast.com/articles/2014/06/05/aplea-to-melinda-gates-stop-stigmatizing-abortion

6. Trump's 'global gag rule' could endanger millions of women and children, Bill and Melinda Gates warn. The Guardian. 14 February 2017. Available from: https://www.theguardian.com/globaldevelopment/2017/feb/14/bill-and-melinda-gatestrumps-global-gag-rule-endangers-millions-womengirls-us-funding

7. Faith Matters: International Family Planning from a Christian Perspective. Christian Connections for International Health. 2014. Available from: 
http://www.ccih.org/Faith-Matters-FP-Christian-

Perspective.pdf

8. See the Universal Access Project's briefing card on

"Sexual and Reproductive Health and Rights and the

Post-2015 Development Agenda" Available from: http://www.unfoundation.org/what-we-do/campaignsand-initiatives/universal-access-project/briefingcards-srhr.pdf and the letter to President Obama calling for expanded U.S. support for abortions abroad, co-signed by John Snow, Inc. Available from: https://americanhumanist.org/news/2015-03-foreignaid-must-guarantee-access-to-reproductive-he/

9. Barot, S. Abortion Restrictions in U.S. Foreign Aid: The History and Harms of the Helms Amendment. Guttmacher Policy Review. 2013; 16 (3).

10. Barot S. A common cause: faith-based organizations and promoting access to family planning in the developing world. Guttmacher Policy Review. 2013; 16(4).

11. Cleland J, Harbison S, and Shah, IH. Unmet Need for Contraception: Issues and Challenges. Studies in Family Planning. 2014; 45[2]: 105-122. https://doi.org/10.1111/j.1728-4465.2014.00380.x

12. Ozler B. Is there an 'unmet need' for birth control. Development Impact. The World Bank. 7 April 2011. Available from: http://blogs.worldbank.org/impactevaluations/is-therean-unmet-need-for-birth-control-0

13. Sedgh G, and Hussain, R. Reasons for Contraceptive Nonuse among Women Having Unmet Need for Contraception in Developing Countries. Studies in Family Planning 2014; 45[2]: 151-169.

14. Singh S, Darroch JE, Ashford LS. Adding it up: the costs and benefits of investing in sexual and reproductive health. New York: Guttmacher Institute and United Nations Population Fund; 2014. Available from: http://www.unfpa.org/adding-it-up

15. Acting on the Call: Ending Preventable Child and Maternal Deaths Report. USAID; 2014. Available from: https://www.usaid.gov/sites/default/files/documents/1 864/USAID_ActingOnTheCall_2014.pdf

16. Gacek CM. Conceiving pregnancy: U.S. medical dictionaries and their definitions of conception and pregnancy. The National Catholic Bioethics Quarterly, Autumn 2009. https://doi.org/10.5840/20099336
17. Humanae Vitae, encyclical letter of Pope Paul VI on the Regulation of Birth, 1968.

18. Hubacher D \& Trussell J. A definition of modern contraceptive methods. Contraception. August 2015; 92(5): $420-421$. https://doi.org/10.1016/j.contraception.2015.08.008

19. Sedgh G, Singh S \& Hussain R. Intended and unintended pregnancies worldwide in 2012 and recent trends. Studies in Family Planning. 2014; 45(3): 301-314. https://doi.org/10.1111/j.17284465.2014.00393.x

20. Santelli J, Rochat, R, Hatfield-Timajchy, K, Gilbert, BC, Curtis K, Cabral R, Hirsch JS, Schieve L, and other members of the Unintended Pregnancy Working Group. The measurement and meaning of unintended pregnancy. Perspectives on Sexual and Reproductive Health. March/April 2003; 35(2). https://doi.org/10.1363/3509403

21. Maternal Mortality fact sheet, updated November 2016. World Health Organization. Available from: http://www.who.int/mediacentre/factsheets/fs348/en/

22. UNICEF, World Health Organization, World Bank, United Nations Department of Economic and Social Affairs Population Division, 2015. Levels and Trends in Child Mortality 2015. United Nations Children's Fund, New York.

23. A prominent example is Jaffe FS. Toward the reduction of unwanted pregnancy. Science. 8 Oct 1971; 174 (4005): 119-127. https://doi.org/10.1126/science.174.4005.119

24. Black, R. E., R. Laxminarayan, M. Temmerman, and N. Walker, editors. Reproductive, Maternal, Newborn, and Child Health. Disease Control Priorities, third edition, volume 2. Washington, DC: World Bank. 2016.

25. Kost K and Lindberg L. Pregnancy intentions, maternal behaviors, and infant health: investigating relationships with new measures and propensity score analysis. Demography. February 2015; 52 (1):83-111. https://doi.org/10.1007/s13524-014$\underline{0359-9}$

26. The bulletin of the World Health Organization credits the founding of the modern family planning movement to the International Planned Parenthood Federation and the Population Council, both of which remain firmly in favor of abortion. Available from: http://www.who.int/bulletin/volumes/86/3/07- 
045658/en/. In recent years, the clearest illustration of the family planning movement's support for abortion can be seen in the near-universal opposition of family planning groups to the U.S. government's Mexico City Policy. For example:

https://www.plannedparenthood.org/files/9814/8486/
3032/Coalition_Statement_Opposing the Global_G ag Rule.pdf.

27. Nowicka W. Sexual and reproductive rights and the human rights agenda: controversial and contested. Reproductive Health Matters. 2011; 19:119-128. https://doi.org/10.1016/S0968-8080(11)38574-6

Competing Interests: None declared.

Correspondence: Rebecca Grace Oas, Center for Family and Human Rights (C-Fam), New York, NY, USA. rebecca@c-fam.org

Cite this article as: Oas R G. Communities of faith and the global family planning movement: friends or foes? Christian Journal for Global Health. July 2017; 4(2):3-9. https://doi.org/10.15566/cjgh.v4i2.183

(C) Oas R G This is an open-access article distributed under the terms of the Creative Commons Attribution License, which permits unrestricted use, distribution, and reproduction in any medium, provided the original author and source are properly cited. To view a copy of the license, visit https://creativecommons.org/licenses/by/4.0/

www.cjgh.org

July 2017. Christian Journal for Global Health, 4(2):3-9. 